\title{
Outcome of Long Segment Transpedicular Screw Fixation in Unstable Thoracolumbar Spine Injury with Incomplete Neurological Deficit
}

\author{
Shah Md. Rezaul Karim ${ }^{*}$, A. K. M. Shahidur Rahman², Syed Abdus Sobhan ${ }^{3}$, \\ Md. Shahidul Islam Akon4, Muhammad Akter Hossain5, Ashraf Ali6, Shah Newas7, \\ Md. Ruhul Quddus ${ }^{8}$, Md. Moshiur Rahman Mollick ${ }^{9}$ \\ ${ }^{1}$ Department of Surgery, Sheikh Hasina Medical College Hospital, Habiganj, Bangladesh \\ ${ }^{2}$ Department of Nephrology, Bangabandhu Sheikh Mujib Medical University (BSMMU), Dhaka, Bangladesh \\ ${ }^{3}$ Department of Orthopaedic Surgery, Sylhet MAG Osmani Medical College Hospital, Sylhet, Bangladesh \\ ${ }^{4}$ Department of Orthopaedic Surgery, Dhaka Medical College Hospital (DMCH), Dhaka, Bangladesh \\ ${ }^{5}$ Department of Anatomy, Chandpur Medical College, Chandpur, Bangladesh \\ ${ }^{6}$ Department of Cardiology, Abdul Malek Ukil Medical College Hospital, Noakhali, Bangladesh \\ ${ }^{7}$ Department of Orthopaedic Surgery, National Institute of Traumatology and Orthopedic Rehabilitation (NITOR), Dhaka, \\ Bangladesh \\ ${ }^{8}$ Department of Biochemistry, Pabna Medical College, Pabna, Bangladesh \\ ${ }^{9}$ Department of Orthopaedic Surgery, Sheikh Hasina Medical College Hospital, Habiganj, Bangladesh \\ Email: ^rezaul1808@gmail.com
}

How to cite this paper: Karim, S.M.R., Rahman, A.K.M.S., Sobhan, S.A., Akon, M.S.I., Hossain, M.A., Ali, A., Newas, S., Quddus, M.R. and Mollick, M.M.R. (2020) Outcome of Long Segment Transpedicular Screw Fixation in Unstable Thoracolumbar Spine Injury with Incomplete Neurological Deficit. Journal of Biosciences and Medicines, 8, 166-187.

https://doi.org/10.4236/jbm.2020.83015

Received: February 24, 2020

Accepted: March 23, 2020

Published: March 26, 2020

\begin{abstract}
Background: Long segment transpedicular screw fixation in thoracolumbar spine injury has gained popularity in the last decades as it provides immediate stability, prevents further risk of complications and allows early mobilization of patient. Objectives: Evaluation of clinical and functional outcome after long segment transpedicular screw fixation in unstable thoracolumbar spine injury with incomplete neurological deficit patients. Methods: This quasi experimental study was conducted at Dhaka Medical College and Hospital (DMCH), Dhaka, Bangladesh from January 2016 to December 2017. A total of twenty four (24) patients with traumatic unstable fracture of the thoracolumbar spine with incomplete neurological deficit underwent long segment transpedicular screw fixation were included in this study. Clinical and radiologic outcomes were assessed pre-operatively and post-operatively. Results: A total of 24 patients aged between 20 - 60 years of both sexes (Male-21, Female-03) were included in this study. Their mean $( \pm S D)$ age was $33.12( \pm 8.57)$ years. Most of them were farmer [09 (37.5\%)] and day labour [08 (33.33\%)]. Motor vehicle accidents were the most common [16 (66.67\%)]
\end{abstract}


Copyright $\odot 2020$ by author(s) and Scientific Research Publishing Inc. This work is licensed under the Creative Commons Attribution International License (CC BY 4.0).

http://creativecommons.org/licenses/by/4.0/ cause of injury and then fall from height [08 (33.33\%)]. The most common level of injury involved was $\mathrm{L}_{1}-10(41.67 \%)$ patients, followed by $\mathrm{L}_{2}-07$ (29.17\%), $\mathrm{T}_{12}-05(20.83 \%)$ and $\mathrm{T}_{11}-02(8.33 \%)$ of the study patients. Burst fracture was the commonest [22 (91.67\%)] type of fracture followed by Chance fracture $[02(8.33 \%)]$. Pre-operative mean $( \pm S D)$ Cobb angle, Kyphotic deformation of vertebral body, Beck index and vertebral compression deformity were $21.83 \pm 4.5$ degrees, $22.09 \pm 4.40$ degrees, $0.78 \pm 2.65$ and 0.18 $\pm 0.93 \mathrm{~mm}$ respectively, after procedure which were significantly $(\mathrm{p}<0.05)$ decreased to $12.5 \pm 3$ degrees, $11.50 \pm 3.5$ degrees, $0.86 \pm 0.40$ and $0.11 \pm$ $0.00011 \mathrm{~mm}$ respectively at final follow up visit. Pain was significantly $(\mathrm{p}<$ 0.001) decreased, while neurologic function and working capability of the patients were improved from pre-operative to final follow up visit. Conclusions: Long segment transpedicular screw fixation is an effective method of treatment in patients having thoracolumbar spine injury with incomplete neurological deficit.

\section{Keywords}

Neurological Deficit, Transpedicular Screw Fixation, Unstable Thoracolumbar Spine Injury

\section{Introduction}

Thoracolumbar junctional area has unique anatomical and biomechanical features because of this region is a transitional region from rigid thoracic segment to mobile lumbar segment [1]. More than $50 \%$ of thoracic and lumbar injuries occur between thoracic $11\left(\mathrm{~T}_{11}\right)$ and lumbar $1\left(\mathrm{~L}_{1}\right)$ vertebrae. Overall $20 \%$ to $40 \%$ of these fractures are associated with neurological deficits [2].

Epidemiological studies showed that thoracolumbar spine fractures are one of the most common fractures in the young healthy population and are more frequent in men (2/3) than in women (1/3). Peak incidence is between the ages of 20 and 40 years [3]. The susceptibility of the thoracolumbar transition is attributed mainly to the following anatomical reasons: The transition from a relatively rigid thoracic kyphosis to a more mobile lumbar lordosis occurs at $\mathrm{T}_{11-12}$. The lowest thoracic ribs $\left(\mathrm{T}_{11}\right.$ and $\left.\mathrm{T}_{12}\right)$ provide less stability. The facet joints of the thoracic region are oriented in the coronal (frontal) plane, limiting flexion and extension while providing substantial resistance to antero-posterior translation. In the lumbosacral region, the facet joints are oriented in a more sagittal alignment, which increases the degree of potential flexion and extension at the expense of limiting lateral bending and rotation [3].

Spinal cord injury due to traumatic accidents of the thoracolumbar spine is a major cause of disability throughout the world [4]. Thoracolumbar fractures are associated with a high incidence of neurological injuries because of the significant kinetic energy required to create these lesions. The transfer of axial loads through the transition from the rigid thoracic kyphosis to the mobile lumbar re- 
gion results in a high incidence of thoracolumbar junction [4]

A stable spine is one that can withstand stress without progressive deformity or further neurologic damage. An unstable spine is one that may lead to an increased deformity or an increased risk of neurologic damage. Instability of the first degree is a mechanical instability with risk of chronic kyphosis. It applies to the severe compression fracture with posterior column disruption as well as to some of the seat-belt type injuries. Instability of the second degree is a neurologic instability. The so-called stable burst fracture falls into this category as further vertical collapse of the fractured vertebra may lead to more retropulsion of bone into the canal in the early post-traumatic phase and to higher risks of post-traumatic spinal stenosis after healing of the fracture. Both of these situations may precipitate neurologic complications in a previously neurologically intact patient. Instability of the third degree is both a mechanical and a neurologic instability. Fracture-dislocations and unstable burst fractures with or without existing neurologic damage are in this category [5].

Minor injuries are represented by fractures of transverse processes, facets, pars intra-articularis, and spinous process of the vertebra. Major spinal injuries are classified into four different categories: compression fractures, burst fractures, seat-belt-type injuries, and fracture dislocations [5].

The neurological examination of the patient means a complete examination of sensory and motor functions along with surface and deep reflexes. In cases of neurological damage, it is necessary to determine the exact grade of mobility impairment and of sensory functions [6]. The recommended method for examining neurological function is the American Spinal Injury Association (ASIA) method and neurological function impairment should be graded according to the ASIA Impairment Scale [7].

Prevention and limitation of neurological injury as well as restoration of spinal stability are the primary goals of management in thoracolumbar fractures. Secondary issues of concern include deformity correction, minimizing motion loss and facilitating rapid rehabilitation. The treatment option chosen should also provide a biological and biomechanical environment conductive to osseous and soft tissue healing, in order to recreate a stable pain free spinal column [8]. The surgical management should point that patient become mobile early with early rehabilitation and the nervous function improves by decompression and fixation. In spite of progress in imaging technique of spine and modern classification system of spine injury there is no generally accepted consensus regarding the type of surgical approach in the treatment of thoracolumbar fractures. Anterior decompression and stabilization have been proposed for cases with severe narrowing of the spinal canal, dislocation, deformities and neurologic compromise. But several authors reported that a long posterior stabilization is frequent used treatment modality [8] [9] [10]. However, posterior approach is less extensive, and most spine surgeons advocate posterior fusion as the treatment of choice for unstable thoracolumbar injuries [9]. Posterio-lateral fusion is considered as the gold standard in the treatment of thoracolumbar burst ftacture [10]. 
Implants for internal fixation of thoracolumbar spine fractures like Harrington rods, Jacobs rods, Luque rods and dorsal plates have several disadvantages. Stability is often not good enough to permit early mobilization of the patient. Slipped hooks, broken rods and loss of correction were observed [11].

The goal of treatment for unstable thoracolumbar injuries is optimizing neural decompression while providing stable internal fixation over the least number of spinal segments. The main goals of surgical treatment are to achieve reduction, stability, early painless mobilization and to provide a reasonable chance of neurological recovery. Anterior or posterior approaches can be used to achieve fusion but the efficacy of either approach is the same [12]. For patients with significant compression of the spinal cord or neural elements, any surgical intervention needs to achieve full decompression of any bone or soft tissue that is pressing over the spinal cord. Decompression of the spinal cord may lead to improved recovery and afford functional benefits for patient in long term [13]. Short-segment pedicle instrumentation (SSPI) is an attractive solution for fast stabilization of vertebral fractures. This approach includes pedicle screw fixation at one vertebra above and one vertebra below the fractured vertebra. Unfortunately, controversy still exists over whether SSPI is a suitable method. Biomechanical and clinical studies pertaining to short segment posterior instrumentation have shown that many cases will eventually fail with weight bearing. Recently, several articles reported the efficacy of segmental pedicle fixation two levels above and the one or two levels below the fractured vertebra for stabilization of unstable thoracolumbar spine fracture and performed this procedure using wider exposure [12] [13] [14].

But there is scarce evidence addressing the outcome of long segment transpedicular screw fixation in unstable thoracolumbar spine injury with incomplete neurological deficit. Therefore this quasi experimental study was conducted in spine surgery department of $\mathrm{DMCH}$, Dhaka, Bangladesh to evaluate the outcome of long segment transpedicular screw fixation in unstable thoracolumbar spine injury with incomplete neurological deficit.

\section{Materials and Methodology}

This quasi experimental study was conducted in the Department of Orthopaedic Surgery, Dhaka Medical College Hospital (DMCH), Dhaka, Bangladesh from January 2016 to December 2017. The study was approved by the Ethical Review Committee, Dhaka Medical College, Dhaka, Bangladesh. A total of twenty four (24) patients with traumatic unstable fracture of the thoracolumbar spine with incomplete neurological deficit underwent long segment transpedicular screw fixation were included in this study following selection criteria. Informed written consent was taken from each participant prior to enrollment. Adult patients (age 20 - 60 years) of both sexes with traumatic unstable fracture of the thoracolumbar spine with incomplete neurological deficit planned for long segment transpedicular screw fixation within one month of injury were included in this 
study. Patients had history of previous spine surgery, complete neurological involvement, bone tumour of spine, infective disease of the spine (TB spine) and patients who had thoracolumbar spine injury with associated head injury or cervical spine injury were excluded from this study. Each study subject was evaluated by history, clinical examinations and investigations. A detailed history of the selected patients was taken regarding socio-demographic, mode of injury, time of injury and relevant other history. A complete clinical (general, local and neurological) examination and radiological evaluation of each study subject were done for proper assessment. Data were collected from history, clinical examination, investigations and follow up findings.

\subsection{Outcome Variables}

Outcome variables were:

\section{Demographic}

- Age.

- Gender.

Clinical

- Mode of injury.

- Fracture level.

- Type of injury.

- Neurological status by ASIA grading.

- Denis's pain and work scale grade.

- Modified Denis criteria.

- Post-operative complication.

\section{Radiological}

- Cobb angle.

- Kyphotic deformation of vertebral body.

- Beck index.

- Measurement of compression of vertebral body.

\subsection{American Spinal Injury Association (ASIA) Impairment Scale [7]}

The American Spinal Injury Association (ASIA) impairment scale or AIS describes a person's functional impairment as a result of a spinal cord injury (SCI). This scale indicates how much sensation a person feels after light touch and a pin prick at multiple points on the body and tests key motions on both sides of the body.

$\mathrm{LT}=$ light touch; $\mathrm{PP}=$ pin prick; $\mathrm{DAP}=$ deep anal pressure; AIS = ASIA Impairment Scale; NLI = neurologcal level of injury.

- Grade-A = Complete. No sensory or motor function is preserved in the sacral segments $\mathrm{S}_{4-5}$.

- Grade-B = Incomplete. Sensory but no motor function is preserved immediately below the neurological level and includes the sacral segments $\mathrm{S}_{4}$ and $\mathrm{S}_{5}$ (LT or $\mathrm{PP}$ at $\mathrm{S}_{4-5}$ or DAP), and no motor function is preserved more than three levels immediate below the motor level on either side of the body. 
- Grade-C = Incomplete. Motor function is preserved at the most caudal sacral segments for voluntary anal contraction OR the patient meets the criteria for sensory function incomplete status [sensory function preserved at the most caudal sacral segments $\left(\mathrm{S}_{4}-\mathrm{S}_{5}\right)$ by LT, PP or DAP], and has some sparing of motor function more than three levels below the ipsilateral motor level on either side of the body. (This includes key or non-key muscle functions to determine motor incomplete status.) For AIS C-less than half of key muscle functions below the single NLI have a muscle grade $\geq 3$.

- Grade-D = Motor function incomplete. Motor function incomplete status as defined above, with at least half (half or more than half) of key muscle functions below the single NLI having a muscle grade $\geq 3$.

- Grade-E = Normal. If sensory and motor functions [as tested with the International Standards for Neurological Classification of Spinal Cord Injury (ISNCSCI)] are graded as normal in all segments, and the patient had prior neurological deficits, then the AIS grade is E. Someone without an initial SCI does not receive an AIS grade.

\subsection{Dennis Pain Scale [5]}

\section{Grade Criteria}

- P1: No pain.

- P2: Occasional minimal pain; no need for medication.

- P3: Moderate pain, occasional use of medications; no interruption of work or activities of daily living.

- P4: Moderate to severe pain, occasionally absent from work; significant changes in activities of daily living.

- P5: Constant, severe pain; chronic pain medications.

\subsection{Denis Work Scale [5]}

A grading system focused on working capability. It is a five-level scale ranging from W1 to W5, as detailed below.

\section{Grade Description}

- W1: Return to previous employment (heavy labor) or physically demanding activities.

- W2: Able to return to previous employment (sedentary) or return to heavy labor with lifting restrictions.

- W3: Unable to return to previous employment but working full-time at a new job.

- W4: Unable to return to full-time work.

- W5: No work, completely disable.

\subsection{Bridwell Fusion Grade [15]}

\section{Grade Description}

- I Fused with remodeling and trabeculae present. 
- II Graft intact, not fully remodeled and incorporated, but no lucency.

- III Graft intact, potential lucency present at top and bottom of graft.

- IV Fusion absent with collapse/resorption of graft.

\subsection{Investigations Required in the Study}

\section{For diagnosis purpose}

- Plain X-ray both antero-posterior \& lateral view of thoracolumbar spine, magnetic resonance imaging (MRI) of thoracolumbar spine in all patients and computed tomography (CT) scan of the spine was done in 6 patients.

For preoperative evaluation

- Relevant investigations were also done for evaluation of general condition and preoperative fitness such as Complete blood count, Serum creatinine. Serum Electrolytes, Random blood sugar, Blood for grouping and Rh typing, HBsAg, Electrocardiography, X-ray chest etc.

For follow up

- Plain X-ray both antero-posterior \& lateral view of thoracolumbar spine.

\subsection{Radiographic Measurements}

In this study, all the radiographic measurements were taken preoperatively, postoperatively and at the time of each follow up visit. Regional kyphosis angle of the vertebral body (Cobb angle) was measured as the angle between the upper and the lower vertebral endplate. Segmental kyphosis (Kyphotic deformation of vertebral body) was measured as the angle between the inferior endplate of the upper adjacent vertebral endplate and the superior endplate of the lower adjacent vertebra. This method of measurements incorporated both discs in the instrumented spine section. The overall disc height was measured as the average of anterior and posterior disc height (Beck index). Follow-up measurements were compared in relation to disc height immediately after the operation. Measurement of compression of vertebral body was taken in millimetres ( $\mathrm{mm}$ ).

\subsection{Surgical Procedure}

A total of 24 patients with traumatic fracture of the thoracolumbar spine were managed surgically by long segment spinal fixation from January 2016 to December 2017. Informed written consent was taken for surgery from each patient prior to the surgical procedure. Internal fixation done by posterior approach as posterior approach is faster and technically simple to carry out and is suitable for emergency conditions. The level of vertebra involved was identified preoperatively by a skin marking under radiological guidance to aid the preoperative vertebral level identification as well as planning of the extent of incision.

The operative procedure was done under general anaesthesia. The patient was kept in prone position on a specially designed padded operating table for the purpose of abdomen hang free to reduce intravenous pressure and per-operative blood loss as a result of collapse of the epidural venous plexus. 
A midline incision was made and extended both proximally and distally according to the requirement. To expose the lamina, the facets and the transverse process; a standard sub-periosteal dissection was carried out using self-retaining retractors to maintain tension on soft tissues during exposure and any bleeding was secured by proper haemostasis using bipolar diathermy.

The injured level of vertebra identified and confirmed by using C-arm or portable X-ray. The lamina of the injured vertebra was removed and decompression of the neural elements was approached by removing the portion of unilateral or bilateral pedicle of the vertebra to provide access for debridement of the burst fracture fragments $\left(360^{\circ}\right.$ decompression) where it caused the compression. The fragments were impacted by specially designed L-impactor or removed adequately by using specially designed curettes. When dural tears were encountered, the neural elements were gently returned to the dural sac, and the dural defect was repaired directly using non-absorbable $6 / 0$ prolene with round body needle. Then we prepared the pedicles two level above and below the involved vertebra. A pedicle awl was then placed into the pedicle \& made a hole advanced slowly down the pedicle, the medial inclination and an appropriate degree of cephaladcauded inclination. Then pedicular screws of adequate length and diameter were inserted. The screw placement was rechecked by $\mathrm{C}$-arm. Then the titanium rod has been measured, cut and fixed rigidly with screws on one side to allow distraction or compression in required situations. Then decompression was checked and confirmed. Interconnecting bars were fixed in the middle of rods. The bony fragments cut from the spinous process during the surgery were repaired and placed postero-laterally for fusion. The wound was closed in layers with a drain kept in situ.

\subsection{Post-Operative Care}

1) Antibiotics and analgesics were administered conventionally.

2) Patients were allowed to turn the body in bed immediately after operation.

3) The drainage tube was removed at 48 - 72 hours postoperatively.

4) Patients were allowed to sit after radiological evaluation with the back resting with a fully custom thoracolumbosacral orthosis (TLSO) 3 - 5 days after operation.

5) Patients who were in grade $C$ or D according to the ASIA grading system, were allowed to walk on walker with thoracolumbosacral orthosis (TLSO) 3 - 5 days after operation.

6) Stitches removal was done on $14^{\text {th }}$ post-operative day (POD).

7) Bowel and bladder training was given depending on requirements of the patient.

\subsection{Post-Operative Follow-Up}

Immediately after surgery, routine lateral and antero-posterior radiographs of thoracolumbar spine were obtained. All patients were followed up till hospital 
stay. Patients were discharged with advised from the hospital on an average $9.9 \pm$ 4.5 days after operation.

After discharge from hospital each patient was asked to follow up at out-patients department (OPD), department of orthopaedic surgery, DMCH, Dhaka, Bangladesh.

1) 1st follow-up after one (01) month of surgery;

2) 2nd follow-up after three (03) months of surgery and;

3) 3rd follow-up after six (06) months of surgery.

At each follow up clinical examination of wound, neurological assessment and plain radiographic studies were obtained in standing position to determine the Cobb angle, Kyphotic angle, Beck index, measurement of compression of vertebral body, progression of the fracture healing, and development of progression of deformity after surgery and instrumentation failure.

Upon pre-operative, post-operative, and follow-up clinical assessment; the patients neurologic function was graded by using the ASIA grading system, the severity of back pain was assessed by using Denis's Pain scale and outcome of the procedure was scored by modified Denis criteria [5].

All patients were counselled in every follow up regarding the role of physiotherapy in their rehabilitation.

\subsection{Data Analysis}

All data were recorded in a pre-tested data collection sheet. Collected data were compiled and presented in the form of tables and charts based on key variables and functional assessment scoring. Categorical data were presented as frequency/percentage and continuous variable was expressed as mean \pm SD (standard deviation). Paired t-test was done to compare pre-operative and post-operative values. The results were analyzed by using statistical package for social science (SPSS) version 20. Level of significance was defined as p-value $<0.05 \%$ at $95 \%$ confidence interval.

\section{Results}

A total of twenty four (24) patients with traumatic fracture of the thoracolumbar spine who underwent spinal surgery in the form of long segment transpedicular screw fixation between January 2016 to December 2017, at the Department of Orthopaedic surgery, Dhaka Medical College Hospital (DMCH), Dhaka, Bangladesh were included in this study. All patients were clinically evaluated and radiologically investigated. Mean time interval between injury and surgery was $13.6 \pm 10$ days (range 5 - 30 days). Mean post-operative period was $9.9 \pm 4.5$ days after operation. Each patient was followed up regularly up to six (6) months after surgery.

\subsection{Demographic Variables of the Study Patients}

Regarding the demographic characteristics, it was observed that out of 24 study 
patients, $21(87.5 \%)$ of them were male $(\mathrm{M})$ and $03(12.5 \%)$ were female $(\mathrm{F})$ with the ratio of 7:1 (M:F). Age ranges of the patients were found between 20 to 60 years. Most of the patients [14 (58.33\%)] were in 20 - 30 years age group followed by [08 (33.33\%)] in 31 - 40 years age group, [01 (4.17\%)] in 41 - 50 years age group and [01 (4.17\%)] in $51-60$ years age group. Mean $( \pm S D)$ age of the study patients was $33.12 \pm 8.57$ year. An analysis of the different job categories showed that the most impacted group in the samples were farmer [09 (37.5\%)] followed by day labour [08 (33.33\%)], student [03 (12.5\%)], housewife [02 (8.33\%)] and service holder [02 (8.33\%)] (Table 1).

\subsection{Mode of Injury}

In terms of trauma that caused the injuries; motor vehicle accidents were the most common [16 (66.67\%)] and then fall from height [08 (33.33\%)] (Table 2).

\subsection{Vertebral Level of Injury}

Regarding the distribution of injuries by vertebral level among the study patients, there were 07 thoracics [T (29.17\%)] and 17 (70.83\%) lumbar (L) injuries. The most common level of injury involved was $\mathrm{L}_{1}-10$ (41.67\%) patients, followed by $\mathrm{L}_{2}-07(29.17 \%), \mathrm{T}_{12}-05(20.83 \%)$ and $\mathrm{T}_{11}-02(8.33 \%)$ of the study patients (Table 3).

\subsection{Type of Fracture [5]}

In this study according to Denis classification; burst fracture was the commonest [22 (91.67\%)] fracture followed by Chance fracture [02 (8.33\%)] (Table 4).

\subsection{ASIA Grading of the Study Patients}

Pre-operatively, there were $14(58.33 \%)$ patients with ASIA grade B, 09 (37.5\%)

Table 1. Distribution of the study patients by demographic variables $(\mathrm{n}=24)$.

\begin{tabular}{ccc}
\hline Variables & Number of patients (n) & Percentage (\%) \\
\hline Age (in years) & & \\
$20-30$ & 14 & 58.33 \\
$31-40$ & 08 & 33.33 \\
$41-50$ & 01 & 4.17 \\
$51-60$ & 01 & 04.17 \\
Sex & & \\
Male & 21 & 87.5 \\
& & 12.5 \\
Female & 03 & \\
Occupational status & & 37.5 \\
Farmer & & 33.33 \\
Day labour & 09 & 12.5 \\
Student & 08 & 8.33 \\
Housewife & 03 & 8.33 \\
Service holder & 02 &
\end{tabular}


Table 2. Mode of injury of the study subjects $(n=24)$.

\begin{tabular}{ccc}
\hline Mode of injury & Number of patients $(\mathrm{n})$ & Percentage $(\%)$ \\
\hline Fall from height & 08 & 33.33 \\
Motor vehicle accidents & 16 & 66.67 \\
\hline
\end{tabular}

Table 3. Vertebral level of injury of the study patients $(n=24)$.

\begin{tabular}{ccc}
\hline Level of Injury & Number of patients (n) & Percentage \% \\
\hline Thoracic & 7 & 29.17 \\
$\mathrm{~T}_{11}$ & 2 & 8.33 \\
$\mathrm{~T}_{12}$ & 5 & 20.83 \\
Lumbar & 17 & 70.83 \\
$\mathrm{~L}_{1}$ & 10 & 41.67 \\
$\mathrm{~L}_{2}$ & 7 & 29.17 \\
\hline
\end{tabular}

Table 4. Distribution of the study patients by type of fracture $(\mathrm{n}=24)$.

\begin{tabular}{ccc}
\hline Type of fracture & Number of patients (n) & Percentage (\%) \\
\hline Burst fracture & 22 & 91.67 \\
Chance type & 02 & 8.33 \\
\hline
\end{tabular}

patients with ASIA grade C and 01 (4.17\%) patients with ASIA grade D levels of neurological deficit.

Post-operatively, there was no [00 (00\%)] patient with ASIA grade A and B, $02(08.33 \%)$ patients were with ASIA grade C, 12 (50\%) patients with ASIA grade D and $10(41.67 \%)$ patients with ASIA grade E levels of neurological deficit (Table 5). According to ASIA grading it was observed that, 1-grade improvement was found in 07 patients, 2-grade improvement was in 13 patients, 3 -grade improvement was in 04 patients and none of the patient was neurologically deteriorated during this study (Table 5).

\subsection{Visual Analogue Score (VAS) to Asses Pain Intensity of the Study Patients}

The mean visual analogue score (VAS) was $3.0 \pm 0.0$ pre-operatively. After surgery that was $1.79 \pm 0.62$ during 1 st follow up visit, $1.07 \pm 0.84$ during 2 nd follow up visit and $0.24 \pm 0.64$ during the $3^{\text {rd }}$ follow up visit. Therefore it was observed that pain intensity of the study patients significantly decreased from preoperative to $1^{\text {st }}$ follow up visit $(\mathrm{p}<0.001)$ and also decreased significantly $(\mathrm{p}<0.001)$ from $1^{\text {st }}$ follow up visit to $2^{\text {nd }}$ follow up visit and subsequent $3^{\text {rd }}$ follow up visit (Table 6).

\subsection{Grading of the Study Patients on Denis Pain Scale}

According to the Denis pain scale, pre-operatively all the study patients were in grade-5 (P-5). Pos-toperatively most of the patients were in grade-1 (P-1) [18 
Table 5. Pre-operative and post-operative status of the study patients according to ASIA grading $(\mathrm{n}=24)$.

\begin{tabular}{|c|c|c|c|c|c|c|c|}
\hline \multicolumn{2}{|c|}{ ASIA grade (Pre-operative) } & \multicolumn{6}{|c|}{ Post-operative ASIA grade (After 6 months follow up) } \\
\hline Grade & Total (n) & & A & B & $\mathrm{C}$ & $\mathrm{D}$ & $\mathrm{E}$ \\
\hline A & 00 & & - & - & - & - & - \\
\hline B & 14 & & - & - & 02 & 08 & 04 \\
\hline $\mathrm{C}$ & 09 & & - & - & - & 04 & 05 \\
\hline $\mathrm{D}$ & 01 & & - & - & - & - & 01 \\
\hline \multirow[t]{2}{*}{$\mathrm{E}$} & 00 & & - & - & - & - & - \\
\hline & & Total & 00 & 00 & 02 & 12 & 10 \\
\hline
\end{tabular}

Table 6. Pre-operative and post-operative pain intensity of the study patients according to Visual Analogue Score (VAS) $(\mathrm{n}=24)$.

\begin{tabular}{ccc}
\hline Stage & $\begin{array}{c}\text { Pain score } \\
\text { Mean } \pm \text { SD }\end{array}$ & p-value \\
\hline Pre-operative & $3.00 \pm 0.0$ & \\
Post-operative $1^{\text {st }}$ visit & $1.79 \pm 0.62$ & $0.001^{\mathrm{s}}$ \\
Post-operative 2 $2^{\text {nd }}$ visit & $1.07 \pm 0.84$ & $0.001^{\mathrm{s}}$ \\
Post-operative $3^{\text {rd }}$ visit & $0.24 \pm 0.64$ & $0.001^{\mathrm{s}}$ \\
\hline
\end{tabular}

$\mathrm{p}$-value reached from Paired $\mathrm{t}$-test, $\mathrm{s}=$ significant.

(75\%)], then grade-2 (P-2) [05 (20.83\%)], then grade-3 (P-3) [01 (04.17\%)] and no patient was found in grade-4 (P-4) and grade-5 (P5) (Table 7).

\subsection{Grading of the Study Patients on Denis Work Scale}

According to the Denis work scale, pre-operatively all the study patients were in grade-5 (W-5). Post-operatively most of the patients were in grade-1 (W-1) [09 (37.5\%)], followed by Grade-2 (W-2) [07 (29.17\%)] and Grade-3 (W-3) [07 (29.17\%)] then Grade-4 (W-4) [01 (4.17\%)], no patient was found in Grade-5 (W-5) (Table 8).

\subsection{Comparison of Radiological Variables of the Study Patients}

Pre-operative mean $( \pm \mathrm{SD})$ Cobb angle was $21.83 \pm 4.5$ degree, that was significantly $(\mathrm{p}<0.05)$ decreased to12.5 \pm 3 degrees at $3^{\text {rd }}$ (final) follow up visit. Pre-operative mean $( \pm$ SD) Kyphotic deformation of vertebral body was $22.09 \pm$ 4.40 degree that was significantly $(\mathrm{p}<0.05)$ decreased at final follow up to 11.50 \pm 3.5 degrees. Pre-operative mean $( \pm \mathrm{SD})$ Beck index was $0.78 \pm 2.65$ and that was significantly $(\mathrm{p}<0.05)$ decreased at final follow up to $0.86 \pm 0.40$. Pre-operative mean $( \pm \mathrm{SD})$ vertebral compression deformity was $0.18 \pm 0.93 \mathrm{~mm}$ and that was significantly $(\mathrm{p}<0.05)$ decreased at final follow up to $0.11 \pm 0.00011 \mathrm{~mm}$ (Table 9). 
Table 7. Pre-operative and post-operative grading of the study patients on Denis pain scale $(\mathrm{n}=24)$.

\begin{tabular}{cccccc}
\hline Grade & P1 & P2 & P3 & P4 & P5 \\
\hline $\mathrm{n}(\%)$ & $\mathrm{n}(\%)$ & $\mathrm{n}(\%)$ & $\mathrm{n}(\%)$ & $\mathrm{n}(\%)$ & $\mathrm{n}(\%)$ \\
\hline Pre-operative & $00(0.0)$ & $00(0.0)$ & $00(0.0)$ & $00(0.0)$ & $24(100)$ \\
Post-operative & $18(75)$ & $05(20.83)$ & $01(4.17)$ & $00(0.0)$ & $00(0.0)$ \\
\hline
\end{tabular}

Values in the parenthesis denote corresponding percentage.

Table 8. Pre-operative and post-operative grading of the study patients on Denis work scale (n-24).

\begin{tabular}{cccccc}
\hline Grade & W1 & W2 & W3 & W4 & W5 \\
\hline $\mathrm{n}(\%)$ & $\mathrm{n}(\%)$ & $\mathrm{n}(\%)$ & $\mathrm{n}(\%)$ & $\mathrm{n}(\%)$ & $\mathrm{n}(\%)$ \\
\hline Pre-operative & $00(0.0)$ & $00(0.0)$ & $00(0.0)$ & $00(0.0)$ & $24(100)$ \\
Post-operative & $09(37.5)$ & $7(29.17)$ & $7(29.17)$ & $1(4.17)$ & $00(0.0)$ \\
\hline
\end{tabular}

Values in the parenthesis denote corresponding percentage.

Table 9. Comparison of pre-operative and post-operative radiological variables of the study patients (n-24).

\begin{tabular}{ccccc}
\hline Variables & Pre-operative & $\begin{array}{c}\text { Immediate } \\
\text { post-operative }\end{array}$ & $\begin{array}{c}\text { At final follow up } \\
\text { (after 6 months) }\end{array}$ & p-value \\
\hline $\begin{array}{c}\text { Cobb angle (degree) } \\
\text { Kyphotic deformation of } \\
\text { vertebral body (degree) }\end{array}$ & $22.83 \pm 4.5$ & $6.99 \pm 1.16$ & $12.5 \pm 3$ & $<0.05^{\mathrm{s}}$ \\
$\begin{array}{c}\text { Beck index } \\
\text { Measurement of }\end{array}$ & $0.78 \pm 2.65$ & $0.79 \pm 3.4$ & $0.86 \pm 0.40$ & $<0.05^{\mathrm{s}}$ \\
compression deformity & $0.18 \pm 0.93$ & $0.19 \pm 0.0001$ & $0.11 \pm 0.00011$ & $<0.05^{\mathrm{s}}$ \\
\hline
\end{tabular}

\subsection{Results of the Procedure at $3^{\text {rd }}$ (Final) Follow up Visit According to Modified Denis Criteria [5]}

According to the modified Denis criteria, the results of the procedure after 06 months of surgery at final follow up visit was excellent in $15(62.50 \%)$ patients, good was in $8(33.33 \%)$ patients and fair was in $1(4.17 \%)$ study patient (Table 10$)$.

\subsection{Distribution of the Study Patients by Post-Operative Fusion on Bridwell Fusion Grade}

According to the Bridwell fusion grade, in this study 14 (58.34\%) cases showed grade I fusion and $10(41.66 \%)$ cases showed grade II fusion at their last $\left(3^{\text {rd }}\right)$ follow up visit. None of the cases showed grade III and grade IV fusion (Table 11).

\subsection{Distribution of the Study Patients by Post-Operative Complications}

Regarding post-operative complications of the procedure; in this study 04 (16.67\%) 
Table 10. The results of the procedure after 06 months of surgery at final follow up visit according to modified Denis criteria $(n=24)$.

\begin{tabular}{ccc}
\hline Modified Denis criteria & Number of patients (n) & Percentage (\%) \\
\hline Excellent & 15 & 62.50 \\
Good & 8 & 33.33 \\
Fair & 01 & 04.17 \\
\hline
\end{tabular}

Table 11. Distribution of the study patients by post-operative fusion on Bridwell fusion grade $(\mathrm{n}=24)$.

\begin{tabular}{ccc}
\hline Fusion Grades & Frequency (n) & Percentage (\%) \\
\hline I & 14 & 58.34 \\
II & 10 & 41.66 \\
III & 0 & 0.0 \\
IV & 0 & 0.0 \\
Total & 24 & 100.0 \\
\hline
\end{tabular}

patients had developed urinary tract infection (UTI) which was responded to antibiotics. Only $01(4.17 \%)$ patient had developed post-operative superficial wound infection which was successfully managed by conservative treatment. No patient was found with implant failure (Table 12).

\subsection{Distribution of the Results According to Functional Outcome}

For valid statistical analysis, outcome categories were regrouped. Excellent and good categories were considered as satisfactory; fair and poor categories were considered as unsatisfactory. In this series, satisfactory results (Excellent and Good) were found in 23 (95.83\%) patients and unsatisfactory result (Fair) was found in 01 (4.17\%) patient (Table 13).

Figure 1 shows the burst fracture at $\mathrm{L}_{1}$ in pre-operative $\mathrm{X}$-ray of a 25 -year old male with lumbar spine injury due to motor vehicle accident.

Preoperative MRI findings of that patient showing burst fracture at $\mathrm{L}_{1}$ in Figure 2.

Figure 3 shows the early post-operative follow up X-ray of that patient after transpedicular screw instrumentation.

Figure 4 shows the corrected vertebral deformity at $\mathrm{L}_{1}$ in follow up X-ray of that patient after one-month of procedure.

Figure 5 shows the final follow up X-ray findings of that patient after six-month of procedure, displaying that vertebral body height is restored at $\mathrm{L}_{1}$ with transpedicular screw instrumentation.

\section{Discussion}

Jeffrey et al. showed that operative management of thoracolumbar injuries is indicated for lesions that are considered to be unstable and to have the potential for further compromise to the neurologic elements [16]. Even in patients with 
Table 12. Distribution of the study patients by post-operative complications $(n=24)$.

\begin{tabular}{ccc}
\hline Post-operative complications & Number of patients (n) & Percentage (\%) \\
\hline Urinary tract infection & 04 & 16.67 \\
Superficial wound infection & 01 & 04.17 \\
Implant failure & 00 & 0.00 \\
\hline
\end{tabular}

Table 13. Distribution of the results according to functional outcome $(n=24)$.

\begin{tabular}{ccc} 
Results & Number of Patients (n) & Percentage (\%) \\
\hline Satisfactory & 23 & 95.83 \\
Unsatisfactory & 01 & 4.17 \\
Total & 24 & 100.0 \\
\hline
\end{tabular}

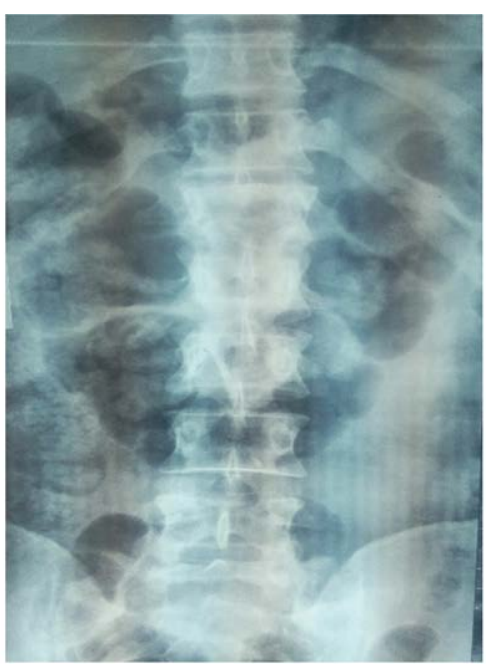

(a)

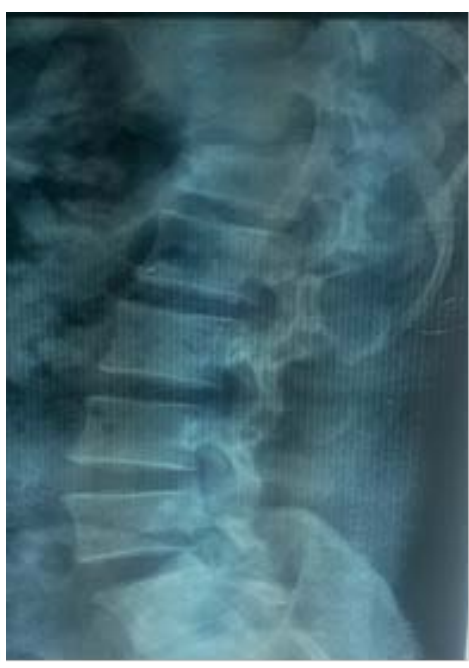

(b)

Figure 1. 25-year-old male with lumbar spine injury, pre-operative X-ray of the patient showing burst fracture at $\mathrm{L}_{1}$. (a) A/P view and (b) Lateral view.

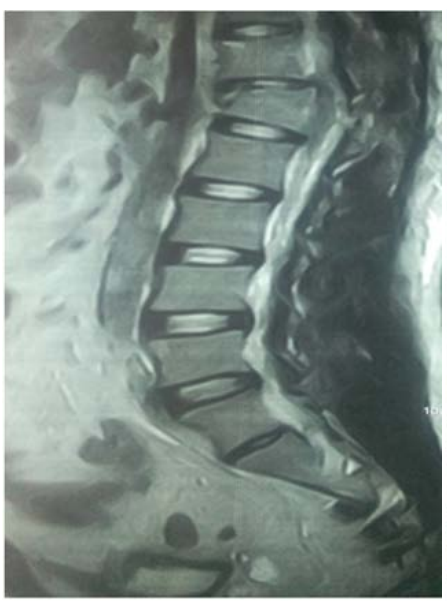

(a)

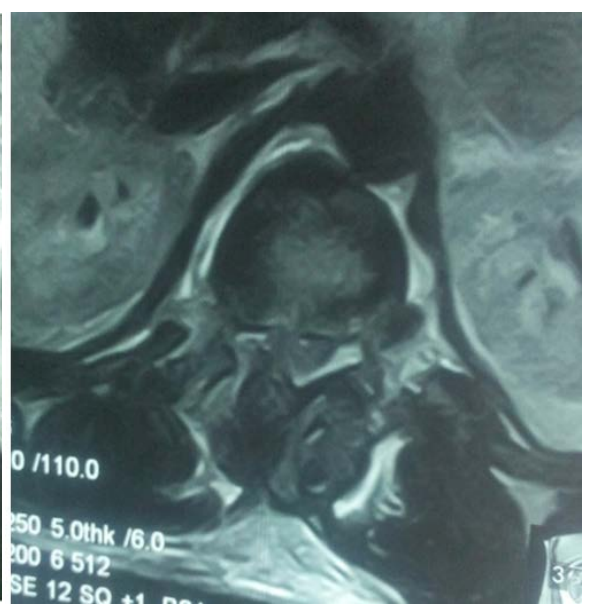

(b)

Figure 2. Pre-operative MRI of the patient showing burst fracture at $\mathrm{L}_{1}$. (a) Sagittal view and (b) Axial view. 


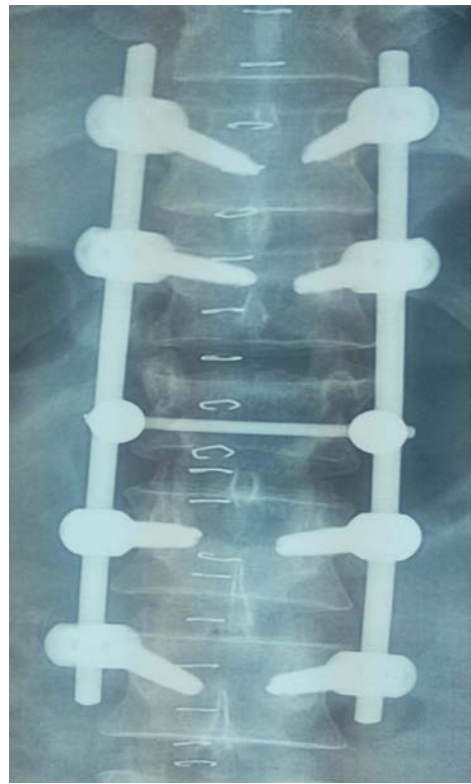

(a)

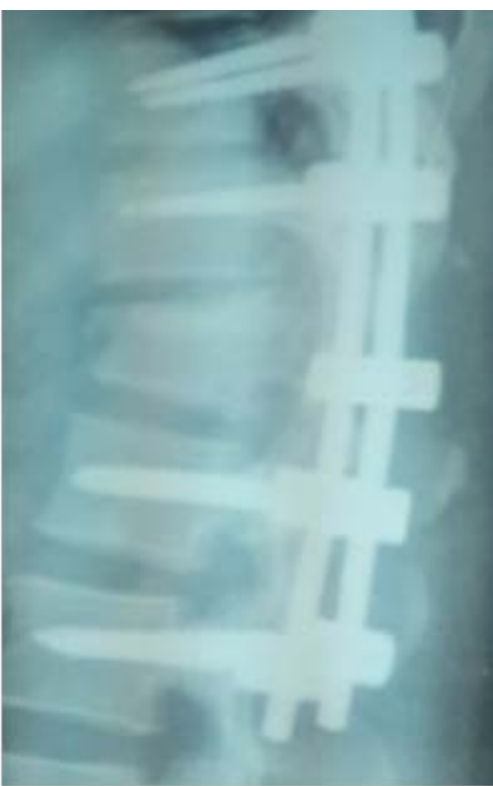

(b)

Figure 3. Early post-operative X-ray of the patient. Transpedicular screw in situ. (a) A/P view and (b) Lateral view.

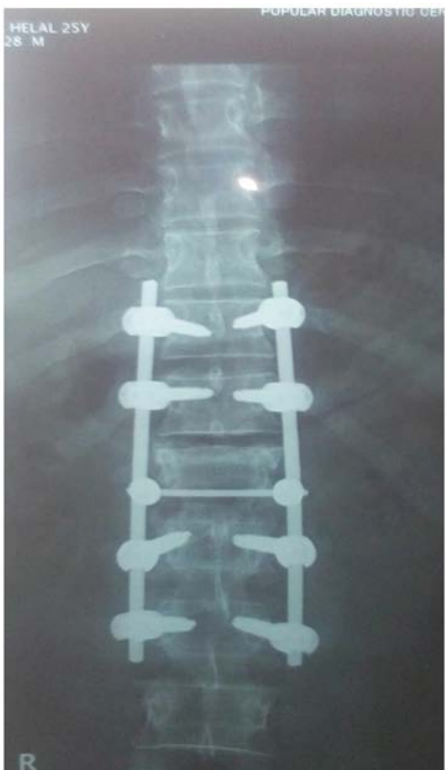

(a)

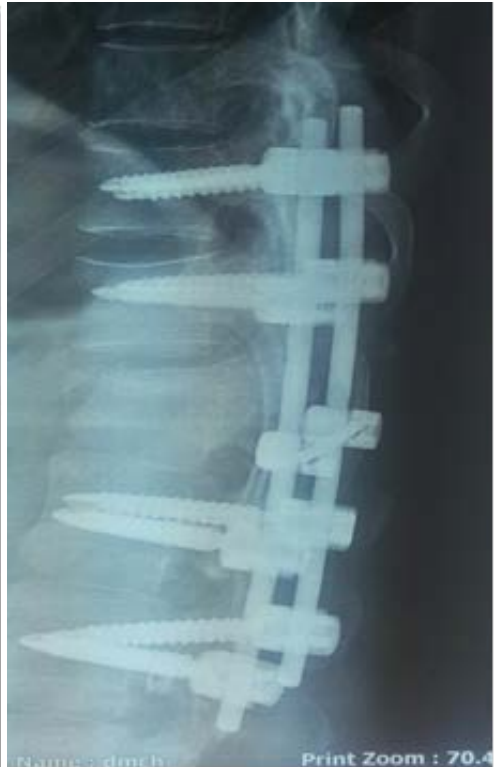

(b)

Figure 4. Follow up X-ray of the patient after one-month of procedure. Transpedicular screw in situ. Vertebral deformity is corrected at $\mathrm{L}_{1}$. (a) A/P view and (b) Lateral view.

complete neurologic lesions, surgical stabilization can allow more rapid mobilization and earlier commencement of physical rehabilitation. Controversy exists as to the treatment of unstable spinal column injuries in patients without neurologic injury. Proponents of initial non-operative treatment believe that good results can be obtained in most cases and that late neurologic deficit, bone deformity, and instability can be corrected. Surgical stabilization facilitates the most 


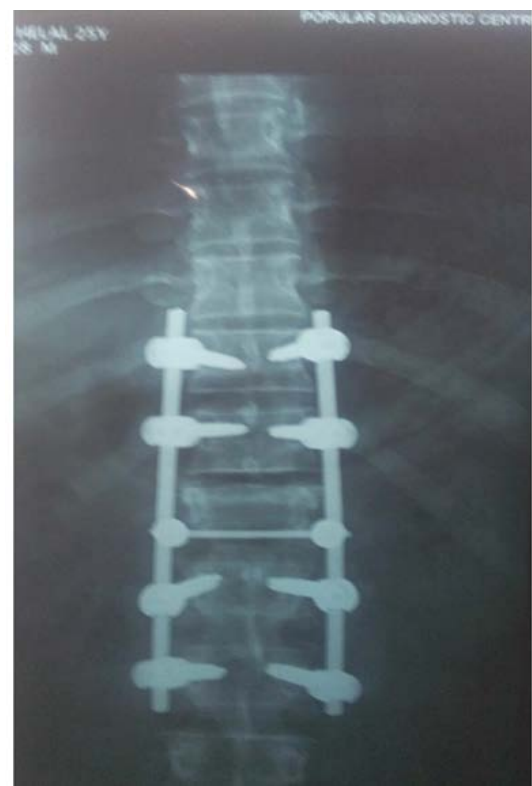

(a)

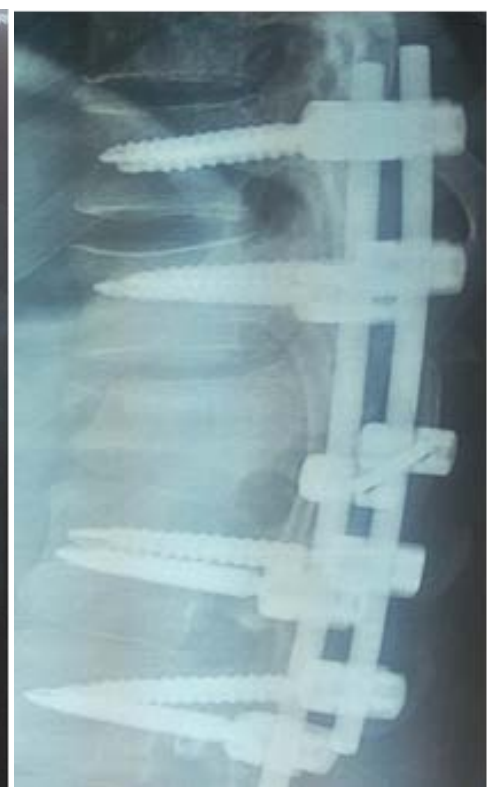

(b)

Figure 5. Final follow up X-ray findings of the patient after six-month of procedure with transpedicular screw instrumentation. Vertebral body height is restored at $L_{1}$. (a) A/P view and (b) Lateral view.

rapid functional return and reintegration into society for patients with unstable fractures [12] [13] [14]. This approach also prevents the late complications of neurologic injury, deformity, and painful instability. The surgical methods needed to correct the sequelae of late instability and fixed deformity are quite complex and fraught with significant morbidity.

A total of twenty four (24) patients with traumatic fracture of the thoracolumbar spine underwent long segment transpedicular screw fixation were included in this study. According to the age they were divided into four groups. Their mean age was $33.12 \pm 8.57$ years (range 20 - 60 years). Wang et al studied on 20 patients with traumatic fracture of the thoracolumbar spine underwent spinal surgery and found that their mean age was 38.4 years (range 17 - 66 years) which was similar to this study [17]. It was reported that thoracolumbar spine fractures were one of the most common fractures in the young healthy population [3] [17].

In this study among total 24 study patients, male were $21(87.5 \%)$ and female were $3(12.5 \%)$ with male to female ratio was 7:1 (M:F). Shang et al. showed that out of total 20 study patients, $16(80 \%)$ were male and 4 (20\%) were female in their study and this finding was accorded to the current study [18]. Therefore it has been observed that thoracolumbar spine fractures are more frequent in men than in women.

Mean $( \pm \mathrm{SD})$ time interval between injury and surgery was $13.6 \pm 10$ days (range 5 - 30 days) in current study. Singh et al. showed mean time interval between injury and surgery was 13.1 days (range 1 - 31 days), which was accorded to this study [9]. 
Regarding the mode of injury of the study patients, motor vehicle accidents were in $16(66.67 \%)$ patients these were the most common and then fall from height were in $8(33.33 \%)$ patients. Sarkari et al. found 9 (64.28\%) patients were injured due to fall from height and $5(35.72 \%)$ patients were injured by road traffic accident out of total 14 study patients [19]. These findings were consistent with current study.

Regarding the vertebral level of injury of the study patients, there were 7 (29.17\%) thoracic (T) and 17 (70.83\%) lumbar (L) injuries. The most common level of injury involved was $\mathrm{L}_{1}$ in $10(41.67 \%)$ patients, followed by $\mathrm{L}_{2}$ in 7 (29.17\%) patients, $\mathrm{T}_{12}$ in $5(20.83 \%)$ patients and then $\mathrm{T}_{11}$ in $2(8.33 \%)$ of the study patients. Khan et al. showed that $\mathrm{T}_{11}$ injury was in 4 (5.97\%), $\mathrm{T}_{12}$ injury in $8(11.94 \%), \mathrm{L}_{\mathrm{I}}$ injury in $37(55.22 \%)$ and $\mathrm{L}_{2}$ injury in $18(26.86 \%)$ of total 67 cases which were similar to this study [12].

In this study, pre-operatively there were 14 (58.33\%) patient with ASIA grade B, 9 (37.5\%) patients with ASIA grade C and 1 (4.17\%) patients with ASIA grade D levels of neurological deficit. Post-operatively, there were $00(00 \%)$ patient with ASIA grade A, $00(00 \%)$ patient with ASIA grade B, 02 (08.33\%) patient with ASIA grade C and 12 (50\%) patients with ASIA grade D and 10 (41.67\%) patients with ASIA grade E levels of neurological deficit. According to ASIA grading it was observed that, 1-grade improvement was in 7 patients, 2-grade improvement was in 13 patients, 3-grade improvement was in 4 patient and none of the patient was neurologically deteriorated during this study. Rehman et al. showed that among 48 study patients two (2) grade of improvement was in 20 (41.66\%) patients and one (1) grade of improvement was in 12 (25\%) patients [20]. These findings were consistent with this current study. Therefore neurologic improvement has been observed among patients with long segment transpedicular screw fixation in thoracolumbar spine fractures.

Regarding radiological outcome variables of the study patients, pre-operative mean Cobb angle was $21.83 \pm 4.5$ degrees and at final follow up that was $12.5 \pm 3$ degrees. Pre-operative mean Kyphotic deformation of vertebral body was 22.09 \pm 4.40 degrees and at final follow up that was $11.50 \pm 3.5$ degrees. Pre-operative Beck index was $0.78 \pm 2.65$ and at final follow up Beck index was $0.86 \pm 0.40$. Pre-operative mean vertebral compression deformity was $0.18 \pm 0.93 \mathrm{~mm}$ and at final follow up that was $0.11 \pm 0.00011 \mathrm{~mm}$. Sapkas, et al. showed that pre-operative Cobb angle was 17.5 degree and at final follow up that was 6 degree, pre-operative Kyphotic deformation of vertebral body was 13 degree and at final follow up that was 4.5 degree, pre-operative Beck index was 0.60 and at final follow up that was 0.92 [21]. These findings were consistent with this current study. Therefore treatment of unstable thoracolumbar burst fractures by long segment transpedicular screw fixation was associated with satisfactory results on the radiological parameters.

According to Bridwell fusion grade [15], 14 (58.34\%) cases showed grade I fusion and $10(41.66 \%)$ cases showed grade II fusion at their last follow up visit (after 6 months of procedure) among total study patients in this study. None of 
the cases showed grade III and grade IV fusion. Khan et al. showed 95\% fusion in their study patients that were similar to current study [12]. Thus it has been observed that long segment transpedicular screw fixation in unstable thoracolumbar burst fracture was effective.

In present study the mean visual analogue score (VAS) score was $3.0 \pm 0.0$ pre-operatively, that was $1.79 \pm 0.62$ during 1 st follow up visit, $1.07 \pm 0.84$ during 2 nd follow up visit and $0.24 \pm 0.64$ during $3^{\text {rd }}$ follow up visit. It was observed that pain significantly decreased from pre-operative to $1^{\text {st }}$ follow up visit $(\mathrm{p}<$ $0.001)$ and also decreased significantly $(\mathrm{p}<0.001)$ from $1^{\text {st }}$ follow up visit to $2^{\text {nd }}$ follow up visit and subsequent $3^{\text {rd }}$ follow up visit. In accordance, Yan et al. showed the pain index significantly improved from $7.18 \pm 1.09$ to $2.84 \pm 0.91$ ( $\mathrm{p}$ $<0.001$ ) in long segment trasnpedicular screw fixation among patients with unstable thoracolumbar burst fracture and reported that the procedure was simple, safe and effective [22].

According to the modified Denis criteria, results of the study patients after 06 months follow up; excellent was found in $15(62.50 \%)$ study patients, good was found in $8(33.34 \%)$ study patients and fair was found in 1 (4.17\%) study patient. Similar finding was reported by Sarkari et al. as showed that good to excellent outcome was $84.6 \%$ [19]. Thus it has been observed that the outcome of the procedure was satisfactory.

Regarding post-operative complications of study patients; in this study, 04 patients $(16.67 \%)$ had developed urinary tract infection (UTI) which was responded to antibiotics and $01(4.17 \%)$ patient had developed post-operative superficial wound infection that was managed conservatively. In this series, Lee et al. showed that, 2 (7.4\%) patients with superficial wound infections responded to antibiotics and 1 (3.7\%) patient with decubitus ulcer required plastic surgery among their total 27 study patients [23]. Therefore the technique of long segment trasnpedicular screw fixation was useful for the treatment of unstable thoracolumbar burst fracture with no neurologic deficit, and fewer complications.

Proper clinical assessment and radiological evaluation of unstable thoracolumbar spine injuries are essential. Still there are considerable controversies over indications of surgery, choice of approach, and length of fusion. In the absence of neurological insult, thoracolumbar injuries can be managed conservatively. In unstable thoracolumbar spine injury with or without neurological deficit, surgical intervention is recommended. Long segment posterior instrumentation using pedicle screw and rod is a better option in management of these patients. Appropriate surgical management and early rehabilitation help to return most of these patients to productive lives earlier.

\section{Conclusion}

Thoracolumbar brust fractures are common in young and male patients. Long segment posterior instrumentation using pedicle screw and rod is an effective method for achieving better neurological recovery, good pain control and fewer 
complications in post-traumatic thoracolumbar fractures. The goals of the modern spinal surgery should focus on early surgical intervention which will enable deformity correction, minimizing motion loss, optimum neurologic recovery and facilitating rapid rehabilitation in patients with unstable thoracolumbar spine injury with incomplete neurological deficit. Further study should conduct for more techniques such as vertebroplasty/kyphoplasty, combined anterior and posterior fixation, and percutaneous pedicle screw fixation regarding this issue. Hopefully, a series of future researches will offer more useful information to spine surgeons.

\section{Limitations of the Study}

It was a single centre study with a relatively small sample size. Moreover, surgeon's heterogeneity and short period of follow up also the mentionable limitations of this study.

\section{Recommendations}

A long-term follow up is necessary to observe the possible advantages of long segment trans-pedicular screw fixation in unstable thoracolumbar spine injury with incomplete neurological deficit. Hence a large multicentre comparative study is required for further evaluation.

\section{Declaration of Conflicting Interests}

The authors declare no potential conflicts of interest with respect to the research, authorship, and/or publication of this article.

\section{References}

[1] Gomleksiz, C., Egemen, E., Senturk, S., Yaman, O., Aydın, A.L., et al. (2015) Thoracolumbar Fractures: A Review of Classifications and Surgical Methods. Journal of Spine, 4, 2. https://doi.org/10.4172/2165-7939.1000250

[2] Meena, S., Sharma, P. and Chowdhury, B. (2015) Management of Thoracolumbar Fractures. Indian Journal of Neurosurgery, 4, 56-62.

https://doi.org/10.1055/s-0035-1558835

[3] Heinzelmann, M. and Wanner, G.A. (2008) Thoracolumbar Spinal Injuries. In: Spinal Disorders (pp. 883-924). Springer, Berlin, Heidelberg.

https://doi.org/10.1007/978-3-540-69091-7_31

[4] Rahman, A., Asif, D.S., Bhandari, P.B. and Sader Hossain, S.K. (2013) A Demographic Study of Thoracolumbar Junction Fracture in a Developing Country and Its Social Impact. Journal of Spine, 2, 2.

[5] Denis, F. (1983) The Three Column Spine and Its Significance in the Classification of Acute Thoracolumbar Spinal Injuries. Spine, 8, 817-831. https://doi.org/10.1097/00007632-198311000-00003

[6] Milenković, S., Saveski, J., Trajkovska, N., Vidić, G. and Radenković, M. (2010) Transpedicular Screw Fixation of Thoracolumbar Spine Fractures. Scientific Journal of the Faculty of Medicine in Niš, 27, 63-68.

[7] Roberts, T.T., Leonard, G.R. and Cepela, D.J. (2017) Classifications in Brief: Amer- 
ican Spinal Injury Association (ASIA) Impairment Scale. Clinical Orthopaedics and Related Research, 475, 1499-1504. https://doi.org/10.1007/s11999-016-5133-4

[8] Ravikanth, M., Babu, T.V.S. and Chandrasekaran, A. (2016) Comparison between Short and Long Segment Transpedicular Fixation of Thoracolumbar Burst Fracture. Journal of Evidence Based Medicine and Healthcare, 3, 996-1001. https://doi.org/10.18410/jebmh/2016/228

[9] Singh, R., Rohilla, R.K., Kamboj, K., Magu, N.K. and Kaur, K. (2014) Outcome of Pedicle Screw Fixation and Monosegmental Fusion in Patients with Fresh Thoracolumbar Fractures. Asian Spine Journal, 8, 298-308. https://doi.org/10.4184/asj.2014.8.3.298

[10] Ge, C.-M., Wang, Y.-R., Jiang, S.-D. and Jiang, L.-S. (2011) Thoracolumbar Burst Fractures with a Neurological Deficit Treated with Posterior Decompression and Interlaminar Fusion. European Spine Journal, 20, 2195-2201.

https://doi.org/10.1007/s00586-011-1875-6

[11] Dick, W., Kluger, P., Magerl, F., Woersdörfer, O. and Zäch, G. (1985) A New Device for Internal Fixation of Thoracolumbar and Lumbar Spine Fractures: The "Fixateur Interne". Spinal Cord, 23, 225-232. https://doi.org/10.1038/sc.1985.38

[12] Khan, I., Nadeem, M. and Rabbani, Z.H. (2007) Thoracolumbar Junction Injuries and Their Management with Pedicle Screws. Journal of Ayub Medical College Abbottabad, 19, 7-10.

[13] Christopher and Good. (2011) Thoracolumbar Spine Trauma. 619-627.

[14] Khare, S. and Sharma, V. (2013) Surgical Outcome of Posterior Short Segment Trans-Pedicle Screw Fixation for Thoracolumbar Fractures. Journal of Orthopaedics, 10, 162-167. https://doi.org/10.1016/j.jor.2013.09.010

[15] Bridwell, K.H., Lenke, L.G., McEnery, K.W., Baldus, C. and Blanke, K. (1995) Anterior Fresh Frozen Structural Allografts in the Thoracic and Lumbar Spine: Do They Work If Combined with Posterior Fusion and Instrumentation in Adult Patients with Kyphosis or Anterior Column Defects? Spine, 20, 1410-1418. https://doi.org/10.1097/00007632-199520120-00014

[16] Spivak, J.M., Vaccaro, A.R. and Cotler, J.M. (1995) Thoracolumbar Spine Trauma: II. Principles of Management. JAAOS-Journal of the American Academy of Orthopaedic Surgeons, 3, 353-360. https://doi.org/10.5435/00124635-199511000-00006

[17] Wang, L., Li, J., Wang, H., Yang, Q., Lv, D., Zhang, W., Tang, K., Shang, L., Jiang, C., Wu, C. and Ma, K. (2014) Posterior Short Segment Pedicle Screw Fixation and TLIF for the Treatment of Unstable Thoracolumbar/Lumbar Fracture. BMC Musculoskeletal Disorders, 15, 40-42. https://doi.org/10.1186/1471-2474-15-40

[18] Yu, S.W., Fan, K.F., Tseng, I.C., Chiu, Y.L., Chen, Y.J. and Chen, W.J. (2002) Surgical Outcome of Short-Segment Fixation for Thoracolumbar Fracture Dislocation. Chang Gung Medical Journal, 25, 253-259.

[19] Sarkari, A., Gupta, D., Sinha, S. and Mahapatra, A.K. (2011) Minimally Invasive Spine Surgery in Acute Dorsolumbar Trauma: An Experience of 14 Cases. Indian Journal of Neurotrauma, 8, 93-98. https://doi.org/10.1016/S0973-0508(11)80007-9

[20] Azam, F. and Shah, M. (2011) Treatment of Traumatic Unstable Thoracolumbar Junction Fractures with Transpedicular Screw Fixation. Journal of Pakistan Medical Association, 61, 1005-1008.

[21] Sapkas, G., Kateros, K., Papadakis, S.A., Brilakis, E., Macheras, G. and Katonis, P. (2010) Treatment of Unstable Thoracolumbar Burst Fractures by Indirect Reduction and Posterior Stabilization: Short-Segment versus Long-Segment Stabilization. 
The Open Orthopaedics Journal, 4, 7-13.

https://doi.org/10.2174/1874325001004010007

[22] Yan, D.L., Pei, F.X., Li, J. and Soo, C.L. (2008) Comparative Study of PILF and TLIF Treatment in Adult Degenerative Spondylolisthesis. European Spine Journal, 17, Article No. 1311. https://doi.org/10.1007/s00586-008-0739-1

[23] Lee, G.W., Jang, S.J., Kim, J.D., Son, J.H. and Jang, J.H. (2013) The Efficacy of Percutaneous Long-Segmental Posterior Fixation of Unstable Thoracolumbar Fracture with Partial Neurologic Deficit. Asian Spine Journal, 7, 81-90.

https://doi.org/10.4184/asj.2013.7.2.81 